is not, therefore, the tension on the walls of the heart which determines the strength of its contraction at its next beat. When, however, we come to measure the volume of the heart, we find that in the isolated heart this is directly proportioned to the work which the heart has to accomplish. Thus we find that the larger the heart-i.e. the more it is dilated during diastole-the greater is the pressure that it will get up at the succeeding contraction or systole.

We may put this in another form, as is shown by continuing our experiment over several hours, when we find that the worse the condition of the heart muscle, the more it must dilate in order to get up an adequate pressure. Other things remaining equal, we thus see that the volume of the heart during diastole is a measure of its physiological condition, and we are not surprised that a failing heart means a dilated heart. Of course there is a limit to this power of adaptation. As the heart dilates it is working at an ever-increasing mechanical disadvantage, and a point will finally arrive at which this disadvantage more than counterbalances the physiological effect of dilatation. The heart then dilates widely and fails to empty its contents. Dilatation of the heart means elongation of the muscular fibres composing its walls, so that we may put the law of the heart another way and say that the longer its muscle fibres the greater is the energy developed at each contraction. But in this form this wonderful power of adaptation possessed by the heart becomes part of the general properties of all muscular tissues, since the same rule applies to the fibres composing our voluntary muscles. Can we obtain any more precise and physiological conception of what is involved in this relationship between length of fibre and strength of contraction? Microscopic examination of the fibres, either of the heart or of voluntary muscle, shows that these are composed of innumerable fibrils, so that internally the muscle is made up of structures presenting an enormous extension of longitudinal surfaces. The more the muscle is stretched, the greater will be the extent of these surfaces. A large amount of evidence, based on the electrical and chemical changes occurring in muscle as a result of excitation, points to the contraction as being essentially a surface phenomenon-a molecular change over the whole of the longitudinal surface which may result in a polarisation or depolarisation of the surface and an increase of surface tension, so that the muscle is a surface tension machine in which there is on excitation a direct conversion of chemical into surface energy. The greater the surface the greater will be the number of molecules involved, so that increased length of muscle must increase at the same time the total chemical changes and the total tension produced by the summation of the surface tension of each fibril.

It is only by such a change of molecular dimensions that we can explain the rapidity of events in a muscle (the insect wing muscle can contract and relax 300 times per second), or the high efficiency of the machine, an efficiency which A. V. Hill has shown may amount to roo per cent. for each isolated contraction, and over a length of time to 50 per cent. As directly measured in the heartlung preparation, we find a mechanical efficiency of about $25-30$ per cent.

\section{Conclusion.}

It is impossible here to enter into the applications of this law of the heart, but so far it has not failed in accounting for the behaviour of this organ under all manner of conditions, either in health or disease. It is important to remember, however, that we are dealing here with the isolated heart. In the natural body the mechanisms which we have studied are fenced round, protected and aided by the complex activity of the central nervous system, which is always acting on the heart, balancing its activity against that of the blood vessels, and co-ordinating it with the events which are occurring in every other part of the body. All these factors must be taken into account when we are endeavouring to form a conception of the total behaviour of this organ under the varying activities of the intact animal.

\title{
A Summer Visit to Jan Mayen Island.
}

\section{By J. M. Wordie.}

IAN MAYEN ISLAND lies in $7 \mathrm{I}^{\circ} \mathrm{N}$. latitude, $8-9^{\circ} \mathrm{W}$. longitude, and is approximately 300 miles north of Iceland, 200 east of Greenland, and 600 west and north-west respectively of Tromsö and Aalesund - the leading hunting ports in Norway. It was possibly discovered in 1607 by Henry Hudson and named "Hudson's Tutches"; the name, nevertheless, by which it is now known commemorates a Dutch seaman, Jan Jacobsz May, who visited the island in 1614 . The evidence for the earlier visit by Hudson can scarcely be regarded as trustworthy. May's voyage, on the other hand, is well supported No. 2723 , VOL. IO9] by documentary evidence. Immediately following its discovery, Jan Mayen became frequented almost every year by rival Dutch and British whalers. As a whaling and sealing centre, however, the island was markedly inferior to Spitsbergen. Its importance was, nevertheless, far from small, and the British Government is said to have made a grant of it to the Corporation of Hull in 1618 . The number of whalers frequenting the island, however, dropped off very considerably about 1635 , the immediate cause being probably a series of bad ice years. 
Scoresby was the first to give a scientific account of the island. His narrative was based on a visit in $\times 817$, when he was ashore for a short while and climbed one of the smaller extinct craters. Berna and Vogt in $186 \mathrm{x}$, Mohn in 1877 , and Rabot in 1892 also published descriptions. The only expedition last century which remained any length of time on the island, however, was that of the Austrian International Circumpolar Station in $\mathrm{I}_{82}-8 \mathrm{z}$. During a fourteen months' stay under Wohlgemuth's leadership the party made full magnetic and meteorological records. 'Their map, which we found very useful and accurate, was the work of von Bobrik. Curiously enough, the natural history was very slightly studied. station for meteorological purposes either last year or this. A satisfactory arrangement was made, and our expedition secured passages in Engineer Ekerold's two ships Polarfront ( 24 tons) and Isfug. len ( 54 tons). On the Norwegian side the affair was now pushed with greater vigour than ever, and after innumerable difficulties Ekerold finally was able to carry his plans into execution.

At Bergen we were met by Prof. Mercanton, of Lausanne, who had long wished to climb the moun. tain, and it was arranged that on reaching the island he should transfer from the Norwegian party to ours. We were now strongly represented in the various branches of science. Musters himself undertook botanical collections, Bristowe and Leth-

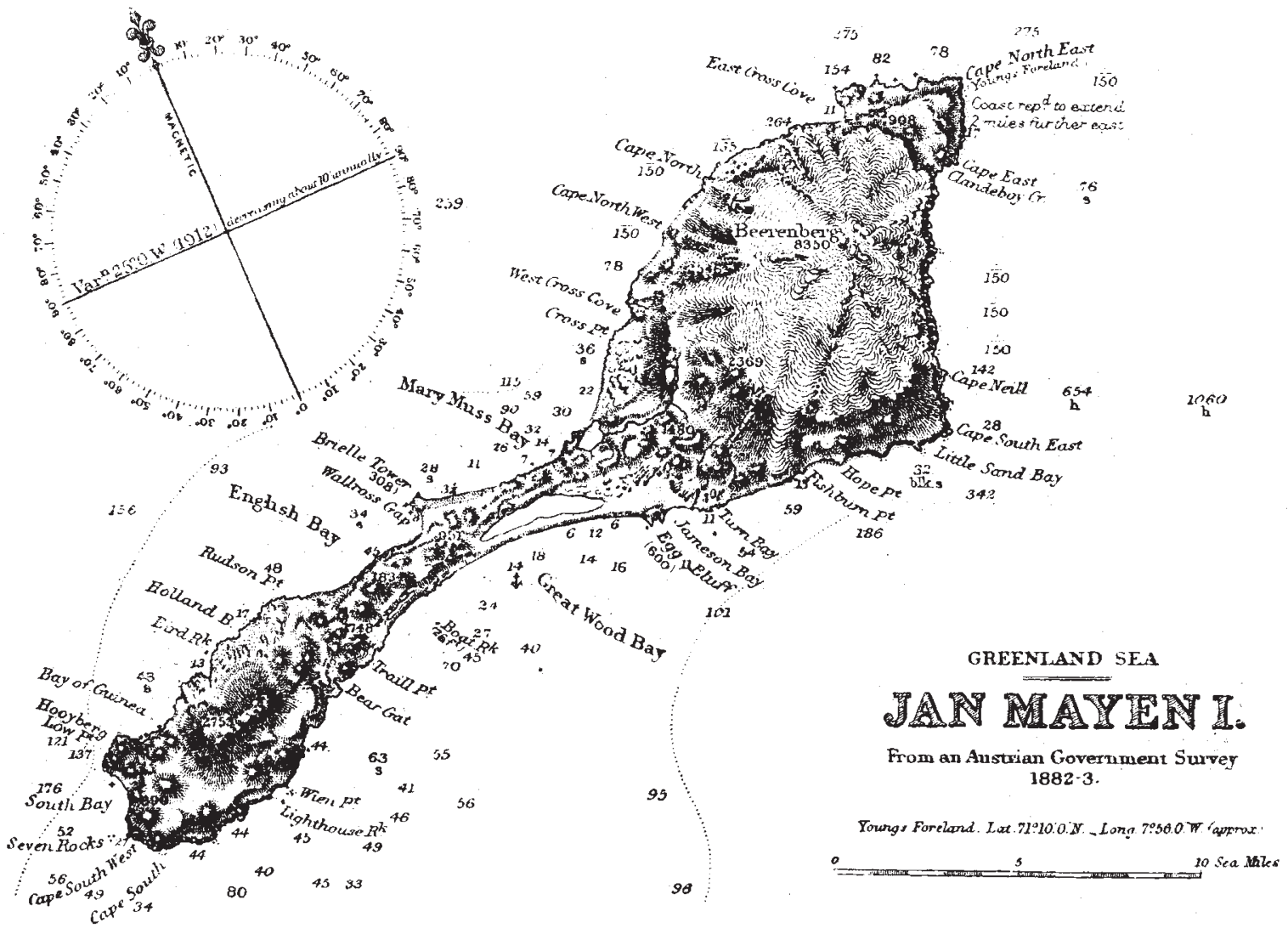

FIG. I. - Reproduced, by permission of the Hydrographer, from an inset on British Admiralty Chart No. $275 \mathrm{I}$.

Last summer's expedition was originated by J. L. Chaworth-Musters at the beginning of last year; the objects were partly to climb Beerenberg, a mountain more than $8000 \mathrm{ft}$. high, and often stated to be a still active volcano, partly to complete the Austrian survey of the island by investigating more minutely its geology and natural history. Musters originally intended to charter a hunting sloop "from Aalesund. This, however, proved unnecessary through the establishment of friendly relations with a Norwegian engineer, who, under the auspices of the Norwegian Government, was hoping to establish a wireless bridge the natural history, and Mercanton's knowledge of glaciology and mountaineering made him a valuable recruit. The party of six was completed by Richmond Brown as "campman," and myself as geologist. Four of us were members of Cambridge University.

After a somewhat rough passage the island was reached on August 7 . It was much too late to think of studying the nesting habits of the birds. It was almost too late to find the plants still in flower. Musters, therefore, accompanied by Bristowe, at once commenced his collecting. The lateness of the 
season also made it advisable immediately to attack the hitherto unclimbed Beerenberg. To make the ascent direct from sea-level seemed hardly practicable, and an advance camp was, therefore, established at $2700 \mathrm{ft}$. on the highest of the frontal moraines. Unfortunately, Brown was not well enough to go farther, and the size of the party was thus reduced to three. Starting on August I I about I. a.m., for there had been some rain during the night, we trudged for some hours up a gently sloping and but little-crevassed ice-slope to a nunatak at a height of $5600 \mathrm{ft}$. 'The real climb now began. Mercanton went first, Lethbridge second, with myself as last'man. 'Two thousand feet of interesting snow- and ice-work brought us finally to the bergschrund not far below the ridge, and after a little delay it was safely negotiated. A stiff climb up a steep snow-wall then brought us to the ridge, and we suddenly found ourselves standing on the rim of a great crater. This was an unexpected and exciting development. The crater was about half-amile in diameter, and from 500 to $800 \mathrm{ft}$. deep. At its northern edge one of the later eruptions had burst the rim and formed a gateway of which the highest part of the mountain is now the western pillar. Since that distant period, however, the crater has become filled with ice, and a much-crevassed glacier now breaks away to the north in a series of striking icefalls, finally reaching the sea (so Mercanton afterwards informed me) as the Weyprecht Glacier. To complete the ascent by following a snow-arête to the actual summit was not long of accomplishment, and gave us a further opportunity of appreciating Mercanton's mountaineering skill. That the summit, deep-covered in rime as it is, has solid rock not far below is certain; scoriaceous lava was collected $50 \mathrm{ft}$. away. Observations on the summit occupied some time, and, fortunately, there were bursts of sunshine sufficient to enable photographs to be taken. It was almost 9 p.m., therefore, before we commenced the return, but a brisk pace was kept up, and a distance which had taken eight hours on the ascent was now covered in three.

Apart from the geological observations, which showed that the Beerenberg eruptions had been exclusively lava, quite the most interesting and perplexing feature is the gentle ice-slope extending from $5600 \mathrm{ft}$. down to the camp at $2700 \mathrm{ft}$. Viewed from a distance, it has all the appearance of an "ice-cap" ; it reminded one very closely of the Hardanger Jökul, for instance. At the time I was inclined to regard it as a new type of piedmont or as an "ice-cap" caused by higher precipitation at intermediate levels. It may be so, but, on the other hand, since returning I have noticed that a similar gentle slope characterises both Mount Vesuvius and Mount Erebus, and it can, therefore, be explained on other grounds. Aneroid observations were taken at regular intervals during the ascent. These give Beerenberg a height of $8090 \mathrm{ft}$. The Austrian figure arrived at by theodolite observations was $8350 \mathrm{ft}$. It is not usual to prefer aneroidto theodolite-determined heights, but as the Austrian triangle was a very bad one $I$ think there may be some justification in this case for adopting a lower ligure than that generally accepted.

Whilst the mountain was being climbed, Musters and Bristowe had been working at lower levels. After hurried preliminary collections round the base camp they transferred their quarters to a small tent eight miles farther down the coast. From this point the southerly parts were within reach. Musters records a most interesting visit to Seven Hollander Bay, interesting not only historically, but also botanically in respect of the more luxuriant yegetation in that quarter. When Musters finally left the island he was able to tabulate forty-three species of flowering plants, of which five had not previously been recorded there; in addition, the lower orders have still to be worked out and his ecological observations put together. The collections have an added interest just now, as they arrived at the Cambridge Botany School simultaneously with collections made last. summer by Prof. Seward in West Greenland, and by Mr. Walton in Spitsbergen. Bristowe's insects are taking longer to name; meantime he has discovered that the spiders are forms met with in the Scottish Highlands; of the flies, etc., only one is native to Britain; the rest are not yet identified. Seventy per cent. of his specimens are new records. for the island.

The successful climb on Beerenberg had revealed a good deal about the geology and glaciology. We realised, however, that on that mountain we were dealing with comparatively recent events in the island's history, and the older chapters, if any, had to be discovered. Lethbridge and the present writer in due course relieved Musters and Bristowe at the tent at the south end. From here we ranged over the more distant and inaccessible parts. Apart from the distances which had to be covered, it was arduous travelling both along the coast and on the screecovered mountain slopes. As the survey was not absolutely exhaustive, additional data may still come to light; meantime the geological record is somewhat as follows : The oldest rocks are coarse and fine augite tuffs ; they are generally covered and hidden by later lavas, but are occasionally seen forming rugged and picturesque cliffs along the coast. The earliest lavas were biotite-trachyte; rocks of this composition are nowhere found at craters still well preserved, but always as old hill features. 'The other and later distinctive lava type is an olivineaugite-basalt rich in alkalis. This rock is found at all the recent craters and also at many older, halfobliterated centres of eruption. A rock of much the same composition, but varying in details, has a widespread occurrence in the form of sills. The south end of the island consists of the older volcanoes; Beerenberg, at the north end, however, must be one of the latest, and round its foot there are many subsidiary cones-e.g. Palffy and Vogt craters, which must also be of comparatively recent date. These are exclusively lava craters. One of the very latest, however, is an ash. cone-Egg Bluff; it has:

NO, 2723 , VOL. IO9] 
a further interest because on the summit there are a few short irregular cracks from which hot steam still issues. Under certain atmospheric conditions these cracks "smoke" quite obviously and this phenomenon was possibly the "eruption" reported by 'Scoresby in 1818 . Scoresty's account is unfortunately written with considerable hesitation. "Smoke" on Egg Bluff scarcely satisfies his description, however. It seems more probable that an ash eruption actually took place at the foot of the western side of Vogt (Scoresby's Esk) crater, possibly in the same spot where the only other authentic eruption, that of $\times 73^{2}$, was observed by the whaler, J. J. Laab. Beerenberg itself has never been observed in activity. There is no evidence of when the first eruptions took place; they may even be post-glacial.

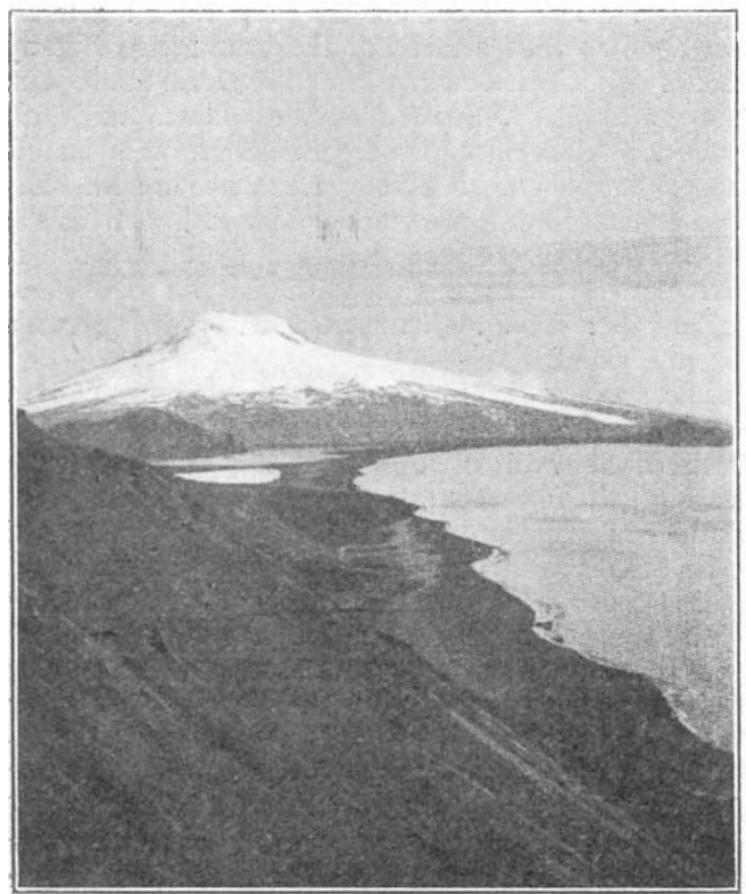

I hoto]

$[W, S$, Bristowe

FIG. 2.-Beerenberg from the south.

As regards glaciology, Prof. Mercanton has supplied me with a brief summary. Glaciers are confined to Beerenberg. Four elemerts are distinguished: (a) the glacier which issues from Beerenberg crater; (b) a "collerette glaciaire," continuous in its middle portion, covering the north and north-east parts of the mountain; $(c)$ an independent system on the eastern flanks; (d) a great "collerette " covering the flanks from north round through west and south to east-south-east. (Part of the latter has already been referred to as the ice-cap feature.) The examination of these different elements shows decreasing glaciation, but whether recent or ancient has not yet been discovered. The rate of movement recorded show's the same order of things as on similar decreasing glaciers in Switzerland. More exact figures, however, will be available when the ground is re-visited.

By the beginning of September it was obvious that the work was now practically complete. Winter weather had already set in, but we were told that we might still make a fair passage. We left the island in Polarfront on September 3. Isfuglen, however, was remaining another fourteen days in order to bring home the men working at the erection of the wireless station. This they soon completed; and the first message had already reached Norway when we made the coastal waters on September 9. Engineer Ekerold has therefore put up a weather station in a spot where it will be of real value-in the "blind corner" whence no weather warnings had previously been available. $\mathrm{He}$ did so

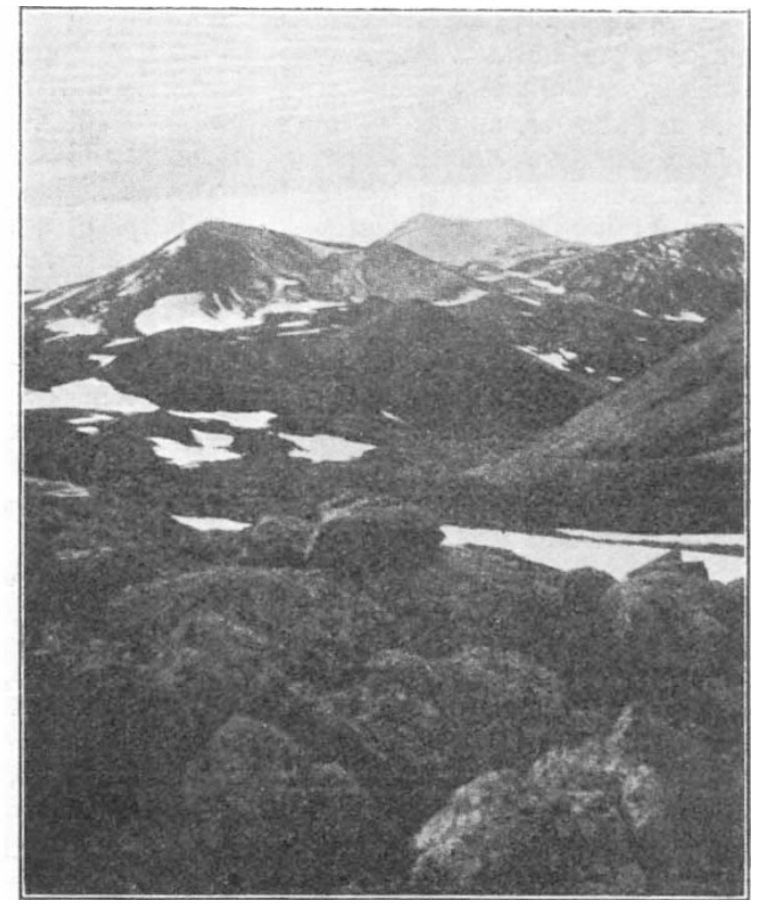

Photo]

[W, S. Bristowe

Fig. 3.-Mountains at south end of Jan Mayen.

under the most difficult and unsuitable conditions. The work involved the unloading of delicate machines from small boats on an unprotected surfridden coast, the overcoming of the difficulties of transport to the site selected, and finally the raising of the masts in adverse wind conditions, and fixing them in frozen ground. Ekerold is now sending daily weather reports to Norway. With the assistance of these it is hoped that it will be possible to forecast the arrival of the northerly and northwesterly gales which come down so suddenly all along the Scandinavian coast, and thus to warn the Norwegian coastal shipping, which has suffered so heavily in the past from the unexpected gales from that "blind corner."

NO. 2723 , VOL. IO97 